\title{
A Framework for Enhancing Students' Participation in E-learning Environment using Motivational Factors
}

\author{
Agbonifo, O. Catherine \\ Department of Computer Science \\ Federal University of Technology, Akure, Nigeria
}

\begin{abstract}
The emergence of technology mediated learning has translated the primitive mode of learning into an enhanced technological mode where learning is not restricted to a particular geographical location, space, time etc. There is more on a new wave of learning strategies and approaches to motivate online learners to engage in learning process tailored through learning paths that lead to successful learning outcome. This paper highlights specific strategies and presents a framework for enhancing students' participation in e-learning environment using motivational factors.
\end{abstract}

\section{General Terms}

E-learning Technology, Motivational Techniques

\section{Keywords}

Technology mediated learning, motivational factors, students' participation

\section{INTRODUCTION}

The advent of Information Technology (IT) has made it essential for learning to take place just-in-time. Learning is the process of acquiring knowledge through study, hands-on practice and teaching. The significant growth of IT has great impact in the way knowledge is transmitted which led to the development of e-learning [5]. There are several definitions of e-learning from the review of literature but it is defined in this paper as "any learning environment where the instructional content is delivered through electronic media" $[8,3]$. The learning content is accessed by students either through standalone or networked of computers with the form of interaction supported by the instructors $[5,12]$.

The success of e-learning system depends on the use of electronic and web-enabling technologies which must follow a scientific approach with systematic procedures and methods. This leads to quality and effectiveness of e-learning systems compare to the conventional learning systems. With the relatively wide acceptability of e-learning systems, there is still problem of high dropout rate of online learners due to inadequate motivational practice in e-learning environment.

According to [11] defined motivation as the person's behaviours and expectations which stemmed from desires that lead to successful learning outcome based on certain learning strategies and approaches in achieving the learning goals. According to [14] stressed that many of e-learning systems are developed to enrich traditional learning system which do not really address the influence of inherent factor such as motivation. Hence, the need to design an e-learning environment that would motivate the students to actively engage and participate in online learning in order to promote higher order of mental skill.

There are several theories that have been proposed to elucidate motivation such as Keller's ARCS and Wlodkowski's Time Continuum Models. Keller's ARCS consists of four main factors such as attention, relevance, confidence and satisfaction [8]. Wlodkowski's time Continuum Model of motivation is described as the foundation of linguistics, cognitive psychology and motivation research which demonstrates the role of motivation in different stages of the learning process $[6,13,2]$. This paper adopts the Keller's ARCS Model with Wlodkowski's time continuum model as motivational techniques to design a framework of e-learning environment that leads to successful active participation of students in learning process.

\section{OVERVIEW OF THEORIES AND MODELS OF MOTIVATION IN E- LEARNING}

This section discusses two of these models which are listed as follows [13]:

\section{a. Keller's ARCS Model}

Keller's theory is represented by ARCS model which consists of four main factors such as attention, relevance, confidence and satisfaction [7]. These factors were established on an extensive review of motivational literature, which metamorphosed into a classification of motivational concepts and theories [9]. Furthermore, the description of the factors is stressed by these researchers as follows: developing elearning system should focus on learners gaining attention, the relevance of the instruction to learner goals and learning styles, ensuring that confidence is built with respect to learning goals and learning outcomes and making the instruction satisfying by the active engagement of learners in learning process that leads to successful learning outcomes.

\section{b. Wlodkowski's Time Continuum Model of Motivation}

Wlodkowski's time continuum model of motivation divides the learning process into three essential stages as described below $[6,2]$ :

i. At the beginning of the learning process, needs assessment should be performed to know the difficulty level of the students relative to the course or curriculum which is prior to developing the instruction; definition of objectives for the course and several approaches and strategies that are required to help the learners develop understanding of the course; the instruction should allow for choice and self-direction in assignments

ii. During the learning process, the instruction should be developed in such a way to stimulate learner to have positive effect on the overall study performance; various motivational techniques that may be used include varying of presentation style or using different modalities of instructions such discussion forum or group work; learner engagement via responses to questions 
iii. The end of the learning process should emphasize on skills or competence or how well the learners have comprehended in the course by using the knowledge acquired to solve realistic problems; frequent feedback method should be used to communicate learning progress and to present learner understanding, misconception and bias.

\section{RELATED WORKS}

There are many factors that have greatly contributed to high drop rate in online learning but the significant impact is that the development of e-learning environment should be reinforced with features that stimulate the online learners to grossly engage in learning process. In [4], described the early researchers' notions on the presentation of information on the Internet in non hypermedia style with the significant capability of allowing the hypermedia learner to have random access to the body of knowledge in their own way and having a degree of control on their learning activities. The author further stressed that the researchers also discovered that due to the huge amount of information stored in the non hypermedia environment, there could be possibility that user looses the sense of information paths within the information network, which could bring disorientation and frustration on the part of users to lose their interest in seeking for valuable knowledge. The suggestion provided to alleviate the situation was to make for appropriate navigational and conceptual tools to enable learners to effectively and efficiently explore the available information.

In [1], developed a motivational scaffold for the Malaysian elearning environment to provide solution to the problem of sustaining and regulating the e-learners' motivation in higher education setting. The findings from the formative evaluation of the tool conducted among forty participants consisting of experts, instructors, and e-learners suggested the capability of the tool to regulate the motivation of the learners. The
Learning console was found to scaffold the e-learners' motivation and could be integrated into the existing learning management system. According to [10] presented an extensive review on different motivational techniques and their possible integration with one another and a phased-in approach was recommended for their implementation.

According to [3] designed a mobile communication tool support to enhance motivation in online courses which was implemented on a mobile phone which extend the use of existing Moodle learning management system. A quasiexperimental research design was used to empirically investigate the influence of these tools on learner motivation using subjective assessment for attention, relevance, confidence, satisfaction, and social ability; and objective assessment for disengagement, engagement and academic performance. The experimental control results indicated that the use of the tools was effective in improving learner motivation, especially in terms of the attention and engagement variables. In summary, there were statistically significant differences in subjective motivation, with a higher level achieved by experimental-group learners (supported by the tools).

\section{SYSTEM DESIGN}

This section presents the architecture and modeling phase of the system.

\subsection{System Architecture}

The system architecture is shown in Figure 1 where the students access the system through the log-in interface using username and password identification number for authentication and verification process. The various activities the students are to engage with are mediated through the application layer and displayed on the interactive interface page.

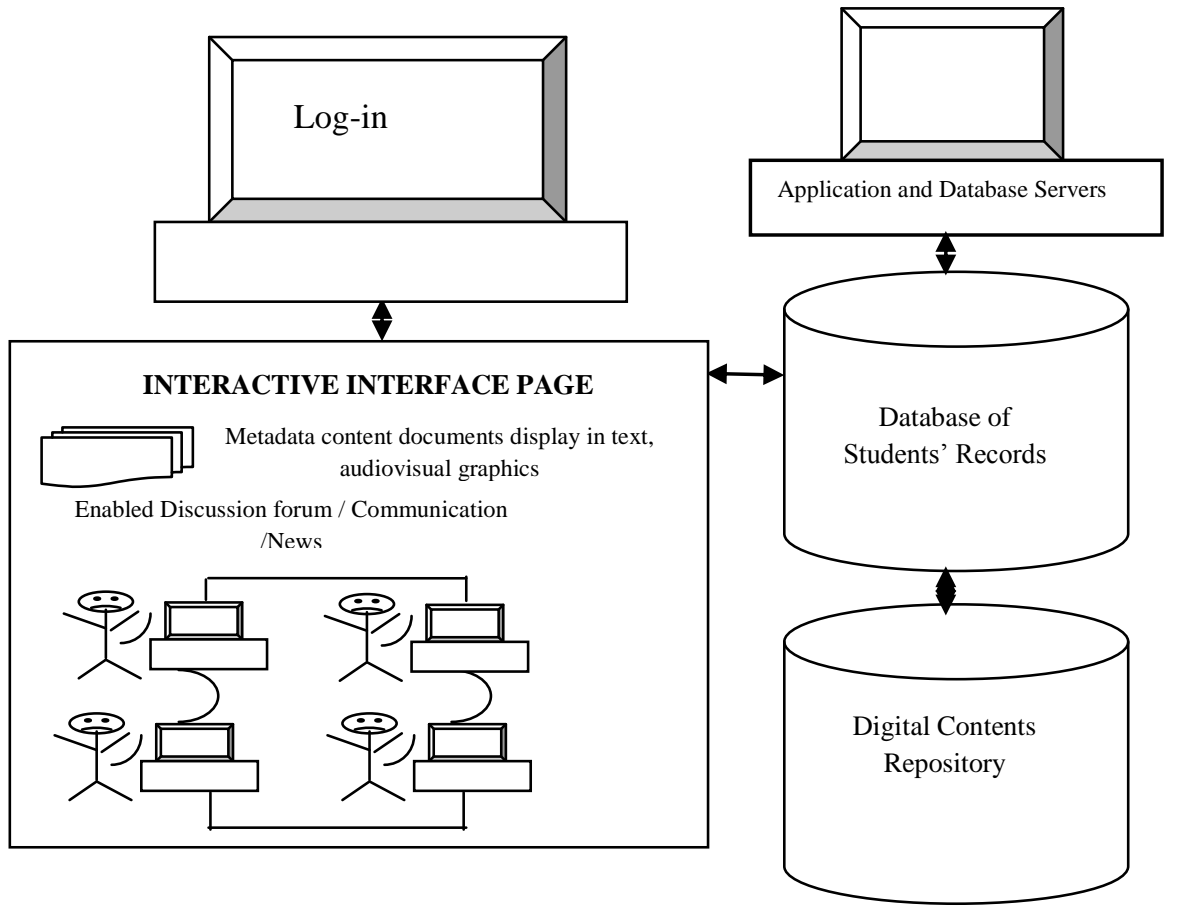

Figure 1. System Architecture of E-learning Environment with Motivational Factors 


\subsection{Modeling Phase}

The motivational models of e-learning system adopted for this research paper are Keller's motivational theory which includes four main factors; Attention, Relevance, Confidence, and Satisfaction; and Wlodkowski's time continuum model which is synchronized with time frame. The various features of the system which relate to the motivational factors are: Goal statement, Graphics and presentation style, discussion forum, communications model and use of emoticons.

The system is accessed by the students through the log-in point as depicted in system architecture. The student's profile is initially created using the following information such as name (first and last), email address, phone number and authentication parameters (username and password) that enable unique identification and subsequent login of each student into the system. Administratively, roles and privileges are assigned to new users created either as instructor or student. The rest of the motivational features are linked through the log-in page if authentication and verification process is successful and these are discussed as follows:

\section{a. Goal Statement}

In the design of e-learning course, it is paramount that learning objectives and goals must be stated at the start of a course or course material. This is incorporated into the system and helps to keep student informed about what is to be achieved. For example, learning objectives for each number of topics that span through the course curriculum must be projected to students in order to give broad understanding of what is expected of the students to learn within a time frame. This enables student to relate with the scope of the subject or course.

\section{b. Discussion Forum}

The e-learning system establishes an interactive environment that allows students to make active contributions to the topic of discuss which supports both synchronous and asynchronous learning. It consists of multi-threads of message where instructors or students can post topical issues as questions relating to the course of study and comments or responses by other students in the group forum can be posted in returns. This medium is used to enhance active involvement of the students and draws their attention to mental thinking and construction of their own knowledge. Also, it supports students by fostering group assistance and this increases confidence in them.

\section{c. Graphics and Presentation Style}

The content of the learning material is supported with graphical representation of the topic on discuss and this always attracts attention. The e-learning environment provides support for instructor to upload the course material in different presentation format such as text, video, audio and images which support different learning style and preference. This provides the students with the flexibility of adopting the style that matches with their learning requirements and this make them to appreciate the relevance of the course material and motivate them to actively participate in the learning process.

\section{d. Communication Model}

The e-learning system supports the communication features such as announcement or news component to communicate important information to the students and a selected option for students to indicate whether the same information should be sent through these media such as email or short message service. Communication messages that are sent to students are to keep them informed of the events within the learning environment such as assignment submission deadline, progress or update on study performance and solution report on difficulty areas. Students' immediate responses to such crucial events or messages demonstrate the level of their satisfaction and confidence in the learning process.

\section{e. Use of emoticons}

The e-learning system incorporates emoticons which represent facial expression of inner reality and these are used to motivate the students to effectively participate in the learning process. This is described in this research paper as facial-icon expression which demonstrates activity response of the students' interactions with the system. When a student has performed outstanding in the exercises or assignments, the student would be presented with "happy" or "pleased" facialicon expression and when sthe has not done well, such student would be presented with "sad" facial-icon expression. The use of emoticons is seen as a way to provide feedback from the system to the students and is describing the internal feelings of the students' interaction with the system in a facial-icon expression.

\section{CONCLUSION}

The focus of developing an e-learning system is to provide an environment where students could be motivated to gainfully engage to participate in online learning. Therefore, this paper presented the framework of e-learning environment that adopts the use of Keller's ARCS and Wlodkowski's time continuum models for increasing motivation on the part of students in e-learning system. The various motivational features presented would make for active engagement and participation of students in online learning process.

\section{REFERENCES}

[1] Alias, N. A. 2012. Design of a Motivational Scaffold for the Malaysian e-Learning Environment. Educational Technology \& Society, 15 (1), 137-151.

[2] Carpenter, J. K. 2011. An Exploratory Study of the Role of Teaching Experience in Motivation and Academic Achievement in a Virtual Ninth Grade English I Course, $\mathrm{Ph} . \mathrm{D}$ thesis in Education submitted to the Graduate School of the University of Florida, pp. 1-267.

[3] Chaiprasurt, C. and Esichaikul, V. 2013. Enhancing Motivation in Online Courses with Mobile Communication Tool Support: A Comparative Study, International Review of Research in Open and Distance Learning, Vol. 14, No. 3, pp. 377-401.

[4] Cheng-Yuan, L. 2000. Student Motivation in the Online Learning Environment Journal of Educational Media \& Library Sciences, Vol. 37, No. 4, pp. 367-375.

[5] Datuk, T. S. and Ali, A. 2004. Issues \& Challenges in Implementing E-Learning in Malaysia, Retrieved from http://asiapacific.odl2.oum.edu.my/C33/F80.pdf, November, 2014.

[6] Hodges, C. 2004. Designing to Motivate: Motivational techniques to incorporate in E-learning Experiences. The Journal of Interactive Online Learning, Vol. 2, No. 3, pp. $1-7$

[7] Keller, J. M. 1999. Using ARCS Motivational Process in Computer-based Instruction and Distance Education. 
New Directions for Teaching and Learning, Educational Technology International, 78, pp. 39-48.

[8] Keller, J. M. and Suzuki, K. 2004. Learner Motivation and E-learning Design: A Multinationally Validated Process, Journal of Educational Media, 29(3), pp. 229239.

[9] Keller, J. M. 2010. Five fundamental requirements for motivation and volition in Technology-Assisted Distributed Learning Environments, Inter-Ação, Goiânia, Vol. 35, No. 2, pp. 305-321.

[10] Keri, B. 2012. A Framework for integrating motivational techniques into e-learning systems, a Master of Science thesis in Information Systems submitted to Athabasca University, Alberta, pp. 1-95

[11] Kiliç-Çakmak, E. 2010. Learning strategies and motivational factors predicting information literacy self- efficacy of e-learners, Australasian Journal of Educational Technology 26 (2), 192-208.

[12] Khaled, M. 2010. E-learning for Tertiary Level Education in Least Developed Countries: Implementation Obstacles and Way Outs for Bangladesh, International Journal of Computer Theory and Engineering, Vol. 2, No. 2, pp. 150-155

[13] Smith, R. 2008. Motivational Factors in E-Learning, Retrieved from http://elgor.at/elearn/Medien/Motivation.pdf, September, 2014.

[14] Sfenrianto, Zainal, A. H. and Heru, S. 2011. The Influence Factors of Inherent Structure in e-Learning Process, International Journal of e-Education, eBusiness, e-Management and e-Learning, Vol. 1, No. 3, pp. 217-222 